\title{
PSIQUiatria INFANTIL SEM PAREDES ${ }^{1}$
}

\author{
Hugo Leonardo Rodrigues Soares, Isabele de Lima de Barros ${ }^{\star}$ \\ Jairo Werner Junior ${ }^{\star \star}$
}

\begin{abstract}
Palavras-Chave: Psiquiatria Infantil. Psicologia. Histórico-Cultural. Educação Médica.
\end{abstract}

INTRODUÇão: A Universidade Federal Fluminense tem sido pioneira no campo da "Psiquiatria Infantil e da Saúde Mental da Criança e do Adolescente", sendo a única Universidade pública brasileira que há mais de 30 anos proporciona essa área de conhecimento aos alunos do curso de Medicina - está presente na grade curricular obrigatória do $5^{\circ}$ ao $8^{\circ}$ períodos, nas disciplinas optativas de Neuropsiquiatria infantil e Desenvolvimento Infantil e no Estágio Supervisionado de Psiquiatria Infantil (internato eletivo). Essa experiência interdisciplinar de formação no campo da Saúde Mental infantil encontra-se fundamentada na perspectiva histórico-cultural, e vem sendo realizada não apenas no curso Médico e no Mestrado de Saúde da Criança e do Adolescente, mas também em outros cursos da UFF: de graduação (Psicologia, Enfermagem, Serviço Social, Odontologia) e de extensão (Curso Interdisciplinar para Problemas Relacionados ao Uso de Álcool e Outras Drogas).

As atividades de ensino encontram-se articuladas com projetos de pesquisa e de extensão, destacando-se o projeto comunitário denominado "Psiquiatria infantil sem paredes", que se caracteriza como atendimento inovador de crianças e adolescentes com transtornos mentais e de comportamento, fundamentado no princípio da "interação social como principal fator constitutivo dos processos psíquicos individuais".

Sabe-se que o conhecimento psiquiátrico hegemônico está relacionado aos paradigmas e modelos mecanicista e organicista - influenciando tanto a compreensão da criança como determinando as classificações e metodologias diagnósticas. Baseado em Vygotsky (1978, 1989), Werner (1997, 2000) propõe, em contraposição, o paradigma histórico-cultural, no qual a criança é compreendida "como ser social e simbólico, constituído intrinsecamente nas e pelas relações sociais, culturais e históricas".

1 Trabalho apresentado na XXVIII Semana Científica da Faculdade de Medicina da UFF, Associação Médica Fluminense, Niterói, Rio de Janeiro.

^ Graduando do curso de Medicina da UFF, monitor das disciplinas de Neuropsiquiatria Infantil e Desenvolvimento Infantil; graduanda do curso de Medicina da UFF, Bolsista de Extensão da PROEX/UFF.

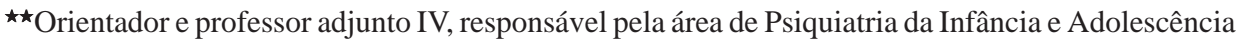
da Faculdade de Medicina (Departamento Materno Infantil) do Centro de Ciências Médicas da UFF. Médico e Doutor em Saúde Mental -UNICAMP e Mestre em Educação - UFF.

Endereço: Departamento Materno-Infantil - Faculdade de Medicina - Hospital Universitário Antônio Pedro (HUAP) - Rua Marquês do Paraná, 303, Centro, Niterói - RJ, CEP 24303-900.

E-mail: jwerne3@attglobal.net 
OвJETIvos: Construir propostas de intervenção no campo da Saúde Mental, fundamentadas no modelo da Psicologia Histórico-Cultural, voltadas para a criança e o adolescente, prioritariamente das camadas populares.

Metodologia: A metodologia se desenvolve em duas etapas. A primeira refere-se aos seguintes procedimentos: identificação das características sociodemográficas e epidemiológicas da clientela atendida (idade, local de residência, encaminhamento, motivo da consulta, diagnóstico/problemática, tempo de tratamento); monitoramento da situação atual (em atendimento, abandono, alta, encaminhamentos, intercorrências); problemas associados (sociais, legais, familiares, escolares, sexuais); atendimentos realizados (individuais: consulta médica, psicoterapia, terapia familiar; e, em grupo: informática, atividades expressivocriativas, teatro, orientação e educação popular com pais e responsáveis). Na segunda etapa, os procedimentos de base mais qualitativa direcionam-se para a criação e valorização da co-construção crítica de novos conhecimentos junto à clientela atendida, principalmente nos espaços coletivos de expressão e educação popular.

Resultados e Conclusões: O trabalho vem possibilitando: a) identificação da necessidade de estabelecer políticas e programas voltados para prevenção e tratamento de problemas relacionados às seguintes questões: fracasso escolar, abuso de drogas, violência doméstica; b) viabilização do acesso a propostas terapêuticas de qualidade e inovadoras; c) ampliação de campo de formação interdisciplinar para alunos da graduação e de pós-graduação; d) despatologização/ desmedicalização de problemas como hiperatividade, desatenção, dislexia, entre outros; e) constituição de espaço de participação, produção e de construção de cidadania para os pais e responsáveis, inclusive com a organização de cooperativa. 